\title{
Positive Impact of Nurses on Infection Control and Practices Prevention Regarding Affect the Clinical Environment
}

\author{
Yasmeen Ghafoor $^{{ }^{*}}$, Mr. Adnan Yaqoob ${ }^{2}$, Mr. Awais Bilal ${ }^{3}$, Ms. Samreena Ghafoor ${ }^{4}$ \\ ${ }^{1}$ RN, MPH, MSN, (Nursing Education Department) \\ ${ }^{2}$ BSN, MSN \\ ${ }^{3}$ (HR Professional) \\ ${ }^{4}$ Lahore School of Nursing, The University of Lahore, Pakistan
}

DOI: $10.36348 /$ sjnhc.2021.v04i04.004

| Received: 23.02.2021 | Accepted: 05.03.2021 | Published: 21.04.2021

*Corresponding author: Yasmeen Ghafoor

\section{Abstract}

Nurses in all part and site can establish leadership in contaminating prevention and control using the knowledge skills and site judgment to initiate proper and immediate infection control nurses play a very important role in infection control. Health care professionals in certain are often showing to several infections healing their daily work nurses have complete awareness and infection control practice. All health care workers whose responsibility to protect the patients from getting infection in hospital and other health care center. Keeping an infection free setting patient's recovery will be promoted and provide the great quality of care. Nurses can do a great agreement to communicate effectively e.g. Nurses should provide the information charge nurses visitors and patient. Provide the proper information patient how to protect themself including support staff in team. Nurses contribution in this war against infection control using the barrier precaution like face marks caps gowns and gloves. Infection control and prevention practices minimize the infection to apply the patient care use the standard Precautions the practices are protect and prevent to spread infections among patients and healthworker and nurses. Frequently hand washing, use of proper personal protective measures sharp safety respiratory care and hygiene good practices of safe injection and use the sterilized instruments. Nightingale mentioned the person as a patient. Atmosphere affects the person. Better atmosphere help to heal the patient soon as compared to polluted. Health is the complete well-being not only to be well. Good environment provide healthy life and prevent the disease. Environment: Poor environment lads to poor health and disease. Healthy environment improve health and healing.

Keywords: Nurses, infection control, patient care.

Copyright (C) 2021 The Author(s): This is an open-access article distributed under the terms of the Creative Commons Attribution 4.0 International License (CC BY-NC 4.0) which permits unrestricted use, distribution, and reproduction in any medium for non-commercial use provided the original author and source are credited.

\section{INTRODUCTION}

Nurses in all part and site can establish leadership in contaminating prevention and control using the knowledge skills and site judgment to initiate proper and immediate infection control nurses play a very important role in infection control.

Nurses are continuously exposed to microbes, several from which can source severe or even toxic infections. Health care professionals in certain are often showing to several infections healing their daily work nurses have complete awareness and infection control practice.

All health care workers whose responsibility to protect the patients from getting infection in hospital and other health care center. Keeping an infection free setting patient's recovery will be promoted and provide the great quality of care. Nurses most of their time spend with patients.

Nurses part in infection control prevention using their waste management training play an energetic role in patient care [1].

Nurses are front line worker clarify infection control Process to the patient the chief nursing superintend play very important role to motivate the nurse to control infection the significant role of nurse in preventing hospital acquired infection nurse as a health care team member who provide the care to patients from infection [2].

Nurses and other health care worker must know several measures for their protection and improve the organizational work and precaution are implement 
Yasmeen Ghafoor et al., Saudi J Nurs Health Care, Apr, 2021; 4(4): 120-125

to prevent the occupational exposure. Nurses play a vital role in prevention the health of patients [3].

The practice of infection control method mostly nurses had poor practices of hand washing before and after attend the patient. Hand washing is a cheapest method to control the transmission of infection patient to patient and other health member. Use of gloves are also simplest and most effective protective measure to transmission of infectious diseases and other infection to the patient to health care worker.

Hand washing and usage of gloves mostly ignorance of insufficient time workload during duty hours especially in situation that calls for immediate intervention positive attitude toward the infection control and waste management reduced to hospital acquired infection. Good practice of infection prevention to easily understanding basic principal and guideline and standard practice implement save the many lives [4].

Nurses can do a great agreement to communicate effectively e.g. Nurses should provide the information charge nurses visitors and patient. Provide the proper information patient how to protect themself including support staff in team. Nurses contribution in this war against infection control using the barrier precaution like face marks caps gowns and gloves

The nurses are very important role in surgical team they provide the care round the clock surgical nurses to understand the all basic of preoperative and post-operative care and infection control and prevention and recognized quality measures in reducing infection [5].

Education communication and information need continue provide help to prevent infection the need for patient education empowerment on their right. The important to realize their right safety threatened by care provider [6].

Nursing students can get the nursing education curriculum, should include information of on infection control so that knowledge on infection prevention and control principles in depth. On-job education should be given on infection control on routine basis as a measure to strengthen the information of nurses on infection control.

The policy makers should ensure that infection prevention and control strategies are made accessible to every nurse. Means such as dis-infectants should be made accessible for nurses to run-through proper infection control. There is need for an enhancement on the nurse patient ratio through employment of more nurses addressing the reason of deficient enough time to exercise proper infection control principles [7].
Everyone is responsible to control and prevent from infection. Patient and health care team play a very important role to control the infectious disease and prevent to spread the infection. Soap and hand sanitizers play important role to control the many disease diarrhea and vomiting spread mostly contaminated hand. Viral disease spread like flue in families and community.

Several factors which can cause health disease relate infections use the inappropriate devices antibiotic and procedures immunosuppression and severe fundamental patient condition insufficient application stander precaution and other some factors to improve the infection control prevention and also improve the health care structures and also increase the knowledge and behaviour change. Infection control programs main goal to ensure that to protect the all patients and communities from events policy formation is necessary for quality improvement [8].

Sterilized technique in intravenous lines insert and other procedures hand hygiene must be done for empty the urinary bag and derange bottle janitors must trained and receive the training in infection control .thermometer oxygen mask and nebulizer kit tubing are separate for each patient or single use patient a great incidence has been reported hand hygiene and other contributing factor [9].

Infection control and prevention practices minimize the infection to apply the patient care use the standard Precautions the practices are protect and prevent to spread infections among patients and healthworker and nurses. Frequently hand washing, use of proper personal protective measures sharp safety respiratory care and hygiene good practices of safe injection and use the sterilized instruments.

To prevent the transmission of infection standard precaution used guideline surgical procedure, for example nurses pay a vital role biopsy surgical intervention teeth extraction apical surgery to keeping hands away from face controlling surface touched ppe removed when leaving duty places do proper hand hygiene. Health care worker touch not only patients skin but come through dirty, contaminated environment proven of medical care hygienic practice to overcome the nosocomial infection. Its effect health care system reduce the risk of infection preventing complete multidimensional Programme.

$80 \%$ healthcare workers did not know to about ppe and proper use of PPE it's very important to provide the complete information about usage healthcare worker satisfaction, laziness, time deficit, skin problems, allergies and some irritant antiseptic cause the transmission of infections [8]. 
Yasmeen Ghafoor et al., Saudi J Nurs Health Care, Apr, 2021; 4(4): 120-125

An institute has been established a hospital infection control committee is accountable for ovulation and planning related all matters of infection control. The main responsibilities of this committee to arrange the educational program and nurses play a main role in implementation of the educational program the fundamental issue of health standard ignorance preventing infection involve concern the concept of three ideas of attitude knowledge and practices [10].

The nurse's role in cleanliness exercise has been highlighted a long period of time. In the middle of nineteenth century Florence Nightingale showed a broad change in the wounded soldiers' care during Crimean war in 1854 typically by improving the hygiene principles. Which reduced the deaths from HCAI intensely [11].

Even currently the nurse plays a vital role in the preventive effort against HCAI. The nurse has most wide ability in nursing profession and become the nature front runner for the co-worker in the day-to-day care of patient comprising hygiene practice [12].

An effective infection control trust on nurse's ability to advice and motivate the staff to retain a good amiability to hygiene practice Enhancement of information is considered to be one of the nurse's core ability, with the vision that the patients should have chance to take best possible part of care which can be provided in each condition [13].

Hospitals are the main spots for the waste. Each department produce left-over and generally it is the left-over of different kinds; healthcare, household and administrative waste. Healthcare waste contains infectious, chemicals, expired pharmaceutical and radioactive things and sharps. Avoiding harm to patients nurses all other health care professionals is essential to complete the Patient safety and excellence care decreasing of health care related infection universal threat such as pandemic covid 19 influenza Ebola virus in these cases nurses pay a great role to reducing preventing transmission of infectious disease safe care provide to patients and also their family .

Infection prevention control nurses with the education additional practical practice and training in infection control expert consultant it is important that health worker and nursing practice and must understanding clinical area trained nurses deliver effectively influence practice. A qualified nurse in infection control highly fulfil their work effectively infection control nurse task to round the visit and identify communicable disease. Nurses are all-rounder in hospital always monitoring controlling and prevent the infection to patient and health care providers she take timely action against wrong practice identify and investigate producers.
Hospital waste must be preserved and predisposed of safely through autoclaving high heat incineration and repressed in safe place suitable and natural ventilation sanitization of recyclable medical device isolation triage a safe and adequate amount of water must be available at any time to awash out and control the infection in great risk units like ICUS, Emergency, operation theaters, Gymea wards. A qualified person accountable directing continuous checking e.g. hand hygiene timely checking feedback performance is provided to stakeholders mainly to administration and management.

The fruitful leader to inspire leadership expertise in the staffs they manage as sound as carrying to their staffs in organization works inspiring motivation is the component of transformational leadership e.g. Private hospital staffs deliver the quality care. Successful leader design the infection control strategies and motivated the staffs and other health professional to overcome the disease burden and provide the quality of care to patients and clarified evidence based practices.

Large private hospital effectively implementation prevention and infection control strategies in this process all administration involved CEO audit officers play very important role to maintain and continue the improvement HR department also play a vital role to maintain record and appreciation for good and hardworking staff .

This approach very useful for best practice and implementation is evidence based practices. Management is broadly measured to vibrant infection control and prevention its determination is to continue improvement reducing risks of healthcare related infections and attain quality improvement continuous effective leadership it's important to achieve the goal for infection control and prevention.

Policy and set of techniques that regulate the control waste is important for the implementation of an actual idea of management the policy and practice set by the hospital Leadership mostly play a vital role in infection control and prevention dealing the colleagues and advising them according to experiences.

The part of leader of infection control and prevention in UK to ensure the effective leadership in infection control and prevention a nurse manager who clinical lead in a sector trained health professional clinical staff and medical officers .hospital administration is responsible for training and arrange the educational program to infection control and prevention practitioners.

Infection control and prevention groups to join yearly infection prevention meetings the competatant manger to help the colleagues and implementation the 
Yasmeen Ghafoor et al., Saudi J Nurs Health Care, Apr, 2021; 4(4): 120-125

best practices to achieve and improve the best patient outcome.

Using the skill and understanding of nurse's practices can help while minimizing complication related to infection can facilities patient recovery some basic strategies exercising use sterile technique and hand hygiene clean and safe environment patient education patient nursing diagnose and additional safety measure [2].

Practices of safe polices avoiding use of unnecessary devices the most important to control the infection and transmission of hospital related infection is hand hygiene. As per Canadian nurses association the program offers guidelines for ethical relationship and decision making, and also use to combining the professional standards, laws and regulation which guides the practice.

The code support as an ethical platform, which encourages the nurses for clean and safe work atmosphere that support the quality, skilled care. All nurses facing personal risk while providing unknown and known infectious disease. Nurses should provide health care by using appropriate safety precautions during natural or non-natural disaster as well as transmissible disease [14].

To promote the patient autonomy giving the patient chance on their beliefs and promote the patient autonomy to provide the right information to the patient to medical decision is essential to this practice empowering patient to improve the safety authorizing patients to promote the behaviour that prevent the nosocomial infection [15].

Florence Nightingale theory on infection control in infection prevention and control in theory nurse.

Provide clean environment for patient to control the infection and prevention nurses provide important.

Role in change of knowledge practice and attitude in infection prevention. Is best for patient condition for healing Night Angle focused on cleanliness hygienic condition sanitation to measure and improving the health care the clean environment effect the patients experience to infection diseases [16].

Reinstating health process and the nurse's function to save life's of patient to restore energy and to recover from the disease prioritizing development of the environmental health Night Angle thought that providing a suitable environment is helpful in early recovery of the patients.
Night Ingle acknowledge for her activities that have carried advanced the best treatment of treatment Nightingle address and provide factors maintain favorable environment to help healing and healthy living practices cleaning well lighted warm and noise free smells recovering process not prevented. The second half of the19th century improved care based on suitable environment to control infection.

Health for goes far the absences of disease according to Nightingale natural restore the health natural preserve health cure the injury or disease other concept nursing is art not a science past background all the its more 150 yrs. Nursing profession is art of caring by Nightingle this art is scientific practice.

Her experience was constructive theory of nightingale environment promoting the health and disease practice backed. After death of nightingale impact of practice of advance nursing leading to image of skilled act mostly respect to environmental problem on health and environment .nightingale mentioned nurse duty in the reality of care to the patients.

The focus of Nightingales model is to change the patient's environment in order to change the patient's health. The environmental factors important to Nightingale's theory are fresh air pure water, sufficient food supplies, efficient drainage, cleanliness of the patient and environment, and light. Nightingale believed if a patient was lacking in one or any of these factors they could experience diminished health.

The nurse's role is to manipulate the environment to create the best conditions for the patient's body to heal. For any given patient, this could mean, more direct sunlight, a well-balanced diet or simply pure water to drink.

The core focus of the Environmental theory is on the patient and not the nursing process itself. Therefore, Nightingale's theory is considered a patientcare theory but rather is adapted to fit the unique needs of every patient. No two patients are affected the same by their environmental factors, therefore the nurse must adjust her patient care as a result.

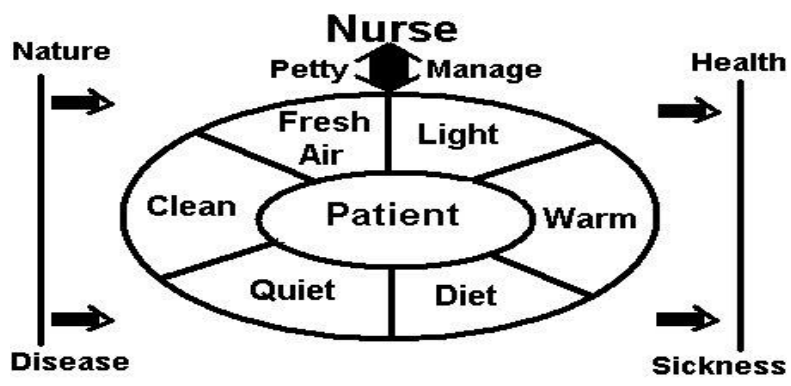


Yasmeen Ghafoor et al., Saudi J Nurs Health Care, Apr, 2021; 4(4): 120-125

The theoretical representativeness related that several of her works to current guideline for nurses in these days. This theory is influence in nurse's practice. Theory makes a significant in the best practices of nursing.

Infection preventionists are responsible for infection prevention and all health care provider are responsible to raise your spirits infection prevention protocols. Accroding to the organization for health care research and quality all unit should have its own infection prevention victors all health professional and also department of infection prevention. Availabilty of the proper set up and supplies to enable infection control and good practices. Manager's key player to provide the useful education and training of Health Care. Mointerning all process practices outcomes and providing the feedback in work place notices and communication. Strengthening of safety climate establishment of cultural change.

Nursing in any kind of situation, she always provide the care and promote the health. The goal of nursing is to provide the best possible healthcare to the patient. Nightingale mentioned the person as a patient. Atmosphere affects the person. Better atmosphere help to heal the patient soon as compared to polluted.

Health is the complete well-being not only to be well. Good environment provide healthy life and prevent the disease.

Environment: poor environment lads to poor health and disease .healthy environment improve health and healing.

Poor or difficult environments led to poor health and disease. Environment could be altered to improve conditions so that the natural laws would allow healing to occur.

\section{RECOMMENDATIONS}

- Providing the awareness training to the nurses during service.

- Highlighting the importance of infection control through print as well as electronic media.

- Revision of the policies and procedures for management of healthcare waste of regular basis.

- Audits and incident monitoring and report to higher authorities.

- Amendment of way of transportation of waste in the hospitals.

- Appointment of team for supervising the waste management.

- Guide the patients regarding infection control and waste management.

\section{REFERENCE}

1. Stone, W. W. (2013). Estimated annual agricultural pesticide use for counties of the conterminous United States, 1992--2009 (No. 752). US Geological Survey.

2. Benson, M. H., \& Garmestani, A. S. (2011). Can we manage for resilience? The integration of resilience thinking into natural resource management in the United States. Environmental management, 48(3), 392-399.

3. Yamin, A. E., \& Boulanger, V. M. (2014). Why global goals and indicators matter: the experience of sexual and reproductive health and rights in the Millennium Development Goals. Journal of Human Development and Capabilities, 15(2-3), 218-231.

4. Nejad, S. B., Allegranzi, B., Syed, S. B., Ellis, B., \& Pittet, D. (2011). Health-care-associated infection in Africa: a systematic review. Bulletin of the World Health Organization, 89, 757-765.

5. Scheiman, M., \& Wick, B. (2008). Clinical management of binocular vision: heterophoric, accommodative, and eye movement disorders. Lippincott Williams \& Wilkins.

6. Kosgeroglu, N., Ayranci, U., Vardareli, E., \& Dincer, S. (2004). Occupational exposure to hepatitis infection among Turkish nurses: frequency of needle exposure, sharps injuries and vaccination. Epidemiology \& Infection, 132(1), 27-33.

7. Ayranci, E., \& Tunc, S. (2004). The effect of edible coatings on water and vitamin $\mathrm{C}$ loss of apricots (Armeniaca vulgaris Lam.) and green $\begin{array}{lll}\text { peppers (Capsicum annuum L.). Food } & \end{array}$ chemistry, 87(3), 339-342.

8. Riasat, R., Malik, M. A., Yousaf, I., \& Imam, K. A. (2019). Knowledge and practices of infection control among healthcare workers in a tertiary care hospital. Pakistan Journal of Physiology, 15(4), 46-48.

9. Shehla, I., Iqbal, A., Ammara, F., Sumaira, R., \& Farah, Z. (2009). A review on Tamarindus indica. Hamdard Medicus, 52(3), 5-13.

10. Ab Hamid, M. R., Sami, W., \& Sidek, M. M. (2017, September). Discriminant validity assessment: Use of Fornell \& Larcker criterion versus HTMT criterion. In Journal of Physics: Conference Series (Vol. 890, No. 1, p. 012163). IOP Publishing.

11. Kelly, J. (2012). Rethinking industrial relations: Mobilisation, collectivism and long waves. Routledge.

12. Björling, E., \& Matiasson, A. (2008). Sjuksköterskans ledarskap i teamet-möjligheter och hinder för sjuksköterskan att arbeta i team.

13. Lindh, M. V., Riemann, L., Baltar, F., RomeroOliva, C., Salomon, P. S., Granéli, E., \& Pinhassi, J. (2013). Consequences of increased temperature and acidification on bacterioplankton community 
Yasmeen Ghafoor et al., Saudi J Nurs Health Care, Apr, 2021; 4(4): 120-125

composition during a mesocosm spring bloom in the $\mathrm{B}$ altic $\mathrm{S}$ ea. Environmental Microbiology Reports, 5(2), 252-262.

14. Cready, C. M., Yeatts, D. E., Gosdin, M. M., \& Potts, H. F. (2008). CNA empowerment: Effects on job performance and work attitudes. Journal of Gerontological Nursing, 34(3), 26-35.
15. Sharp, N., Kuntz, A., Brubaker, C., Amos, S., Gao, W., Gupta, G., ... \& Mascareñas, D. (2014). A bio-inspired asynchronous skin system for crack detection applications. Smart Materials and Structures, 23(5), 055020.

16. Hegge, M. (2013). Nightingale's environmental theory. Nursing science quarterly, 26(3), 211-219. 